\title{
Studi Rancang Bangun Antenna J-Pole pada Komunikasi Aerodrome Surface
}

\author{
Moch Rifai \\ Politeknik Penerbangan Surabaya \\ J1. Jemur Andayani I, No. 73 Surabaya 60236 \\ Email: rifai.moch@poltekbangsby.ac.id
}

\begin{abstract}
Abstrak
Komunikasi permukaan bandar udara ( aerodrome surface) membutuhkan peralatan dengan mobilitas tinggi, terutama peralatan yang terpasang pada mobil patroli landas pacu. Penelitian ini bertujuan mendapatkan rancangan antenna dengan ketahanan tinggi terhadap mobilitas mobil patroli landas pacu dengan pola pancaran omnidirectional. Pada penelitian ini dilakukan perancangan dan simulasi antena J-Pole untuk VHF pada frekuensi $126 \mathrm{MHz}$ dengan menggunakan software CST 2014. Antena J-Pole dirancang menggunakan bahan Besi (Fe) agar tahan terhadap medan mobilitad mobil patroli. Hasil simulasi menunjukkan band frekuensi operasi / band width yang didapatkan dari selisih nilai frekuensi terendah dari VSWR $<1: 1.5$ dan nilai frekuensi tertinggi dari VSWR<1:1.5.sebesar 3.49 Mhz. Frekuensi kerja dari rancangan antenna dengan nilai VSWR terendah 1.23 adalah $125.9 \mathrm{MHz}$. Hasil simulasi juga menunjukkan lebar band yang sama diperoleh dengan return loss $<-10 \mathrm{~dB}$ pada rentang rekuensi $123.99 \mathrm{MHz}$ sampai dengan 127.49 $\mathrm{MHz}$ dengan bandwidth $3.70 \mathrm{MHz}$. Pola radiasi antena hasil simulasi menggambarkan omnidireksional dengan gain pengukuran pada frekuensi $126 \mathrm{MHz}$ sebesar $3.08 \mathrm{~dB}$.
\end{abstract}

Kata Kunci: Aerodrome surface communication, J-Pole antenna

\section{PENDAHULUAN}

Setiap Bandar udara memiliki fasilitas elektronik dasar untuk kepentingan komunikasi, navigasi dan alat bantu pendaratan. VHF $A / G$, very high frequency air to ground communication sebagai salah satu alat komunikasi penerbangan menjadi syarat mutlak beroperasinya suatu bandara. Pesawat pemancar dan penerima yang beroperasi pada frekuensi $118 \mathrm{Mhz}$ sampai dengan 136.975 Mhz dengan extended band pada frekuensi 112 Mhz sampai dengan $155.975 \mathrm{Mhz}$ dengan power mulai 5 watt sampai dengan 50 watt ini memenuhi kebutuhan komunikasi antara pilot dengan petugas Air Traffic Controller (ATC). (System, 2014)

Sesuai dengan KM no 27 tahun 2005 tentang Pemberlakuan Standar Nasional Indonesia (SNI) 03-7097-2005 Mengenai Peralatan Komunikasi Darat Udara Berfrekuensi Amat Tinggi (VHF Air Ground) di Bandar Udara Sebagai Standar Wajib memberikan batasan penggunaan frekuensi aerodrome surface untuk komunikasi permukan bandar udara pada range frekuensi 123.5-129.675 Mhz. (Perhubungan, 2005)

Untuk memantau keamanan area sekitar bandara khususnya area appron sampai dengan runway, petugas keamanan bandar udara (aviation security) dilengkapi dengan mobil patroli dengan komunikasi VHF airband. Hal ini diperlukan mengingat aktifitas mereka berhubungan langsung dengan area pergerakan pesawat di darat. Untuk mengantisipasi dan mencegah hal - hal yang tidak diinginkan mereka harus selalu memantau pergerakan pesawat melalui peralatan radio telekomunikasi VHF aerodrome surface communication. 
Sebuah desain antenna yang handal, tahan terhadap mobilitas kendaraan yang tinggi dan mampu berperasi pada mode pancar omnidirectional diperlukan. Sebuah antenna dengan bahan besi dan tidak memerlukan ground reflected dapat di desain dengan model J-Pole

Penelitian ini focus pada desain antenna J-Pole untuk penggunaan luar ruangan /outdor dengan frekuensi 123.5-129.675 Mhz untuk kepentingan monitoring traffic pada area Aerodrome Surface Ares di kawasan Bandar Udara.

\section{METODE PENELITIAN}

\section{Dasar perancangan antenna.}

Antenna adalah bagian penting dari system transceiver dimana energy ditangkap dan ditransfer ke rectifier. Antena berfungsi sebagai pengubah gelombang elektris pada saluran transmisi menjadi gelombang elektromagnetik pada udara bebas, dan juga sebaliknya (Balanis, 2005). Ada banyak tipe antena berdasarkan bentuk, pola radiasi, dan karakteristik lainnya. Pemilihan antena J-Pole sebagai antena utama pada penelitian ini karena berbagai keunggulan yang dimilikinya, seperti kinerja yang bagus untuk penggunaan komunikasi bergerak atau tetap, dapat digunakan secara dualband pada pita VHF dan UHF, serta tidak memerlukan ground plane sehingga relatif mudah untuk dibuat sendiri dengan bahan-bahan yang murah (Griffith, 2000) (Reynante, 1994)

Desain dasar dari sebuah antena J-Pole adalah terdiri dari dua elemen, yaitu sebuah elemen $3 / 4 \lambda$ dan sebuah elemen $1 / 4 \lambda$ yang terhubung pada masing-masing salah satu ujungnya dengan logam konduktor sejenis. Feedpoint dari antena ini terletak melintang horizontal di atas elemen penghubung tersebut (Kubichek, 2008) Elemen penghubung dari elemen $3 / 4 \lambda$ dan elemen $1 / 4 \lambda$ dibentuk dengan cara membengkokkan material antena sebesar 180 derajat pada seperempat ujungnya dengan jari-jari kelengkungan sebesar setengah dari jarak antara elemen $3 / 4 \lambda$ dan elemen $1 / 4 \lambda$. Dengan cara tersebut maka antena J-Pole ini akan nampak seperti huruf "J" (Lesmana, 2009).

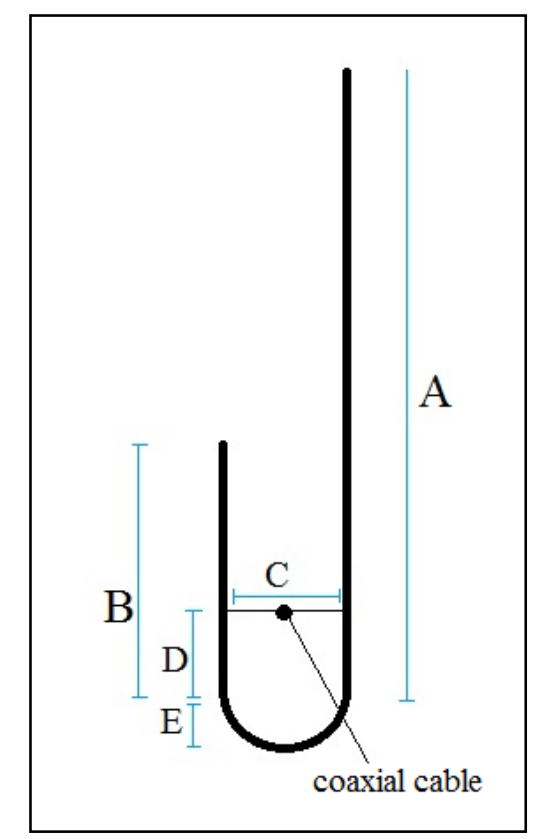

Gambar 1. Desain antena J-Pole 
Bagian A adalah elemen $3 / 4 \lambda$ dan bagian B adalah elemen $1 / 4 \lambda$. Nilai dari lambda dapat dicari melalui persamaan (1) (Hall, 1974) berikut ini:

$$
\lambda=\frac{300}{\mathrm{f} .} \mathrm{k}(1)
$$

di mana:

$\lambda=$ panjang gelombang (meter)

$\mathrm{f}=$ frekuensi kerja yang digunakan $(\mathrm{MHz})$

$\mathrm{k}=$ velocity factor $(0,95)$

Bagian $\mathrm{C}$ adalah letak dari dari feedpoint antena J-Pole. Panjangnya sama dengan jarak antara elemen $3 / 4 \lambda$ dan elemen $1 / 4 \lambda$. Bagian D adalah jarak antara feedpoint dengan bagian paling bawah dari elemen penghubung yang berbentuk melengkung. Sementara bagian E adalah radius dari elemen penghubung sebesar setengah dari panjang elemen C. Panjang elemen C dan D adalah tidak kritis (Griffith, 2000). Hal tersebut berarti berarti tidak ada patokan tertentu mengenai panjangnya. Oleh karena itu pada simulasi perlu dilakukan metode trial and error untuk mendapatkan panjang optimal berdasarkan nilai-nilai parameter antena yang dihasilkan.

Rancangan antena J-Pole merujuk pada Gambar 2 menggunakan persamaan (1) dengan frekuensi kerja $126 \mathrm{MHz}$ yang merupakan frekuensi tengah dari lebar pita frekuensi 123.5 MHz-129.675 MHz. Bahan konduktor yang digunakan adalah kawat besi berdiameter $4.5 \mathrm{~mm}$. Berdasarkan persamaan (1), panjang dari elemen $3 / 4 \lambda$ adalah $171.31 \mathrm{~cm}$ dan elemen $1 / 4 \lambda$ sepanjang $57,10 \mathrm{~cm}$. Untuk panjang elemen $\mathrm{C}$, D, dan $\mathrm{E}$ adalah tidak kritis, dan karena karakteristiknya tersebut digunakan metode trial and error pada proses simulasi antena menggunakan CST Studio Suite 2014 untuk mendapatkan panjang yang optimal. Pilih CST Microwave Studio pada jendela awal CST Studio Suite 2014 untuk menggambar desain antena J-Pole dan mendapatkan nilai-nilai parameter antena berdasarkan simulasi. Untuk menggambar pola antena J-Pole pada bidang gambar digunakan menu "Line" dan "Arc" dari dropdown menu dari menu utama "Curve". Desain antena ini merujuk pada Gambar 2 dan Persamaan (1). Ada 3 desain antena J-Pole yang disimulasikan dan diuji pada penelitian ini dengan variasi pada panjang elemen A,B,C, D dan E. Rincian dari dimensi-dimensi ketiga antena tersebut dapat dilihat pada Tabel I.

\begin{tabular}{|c|c|c|c|c|c|}
\hline \multirow[b]{2}{*}{ Rancangan } & \multicolumn{5}{|c|}{ Panjang Elemen (mm) } \\
\hline & $\mathrm{A}$ & $\mathrm{B}$ & $\mathrm{C}$ & $\mathrm{E}$ & $\mathrm{D}$ \\
\hline 1 & 1770 & 590 & 54 & 27 & 59 \\
\hline 2 & 1752 & 584 & 70 & 35 & 40 \\
\hline 3 & 1713.1 & 571.0 & 57.1 & 22.8 & 59.4 \\
\hline
\end{tabular}

Setelah pola antena tergambar, perlu didefinisikan meterial antena menggunakan dropdown menu "Circle" dan "Sweep Curve" dari menu utama "Curve". Tentukan material pada kotak dialog "Sweep Curve" dengan Iron (Fe) dan atur radiusnya dengan 0,2 cm. 


\section{HASIL SIMULASI DAN PEMBAHASAN}

Pada umumnya teknik pembuatan antena J-Pole dilakukan dengan material batang rod, pipa tubing, maupun kabel TV twin-lead. Namun setelah melakukan percobaan pada simulasi di perangkat lunak CST Studio Suite 2014 dimungkinkan untuk menyusunnya dari suatu bahan semacam kawat. Pada penelitian ini material yang digunakan adalah kawat besi berdiameter $4 \mathrm{~mm}$. Material besi dipilih karena besi dengan diameter 40mm dipandang cukup kuat dipasang pada mobil patroli landas pacu.

Parameter-parameter antena yang diuji adalah frekuensi kerja, VSWR, return loss, bandwidth, gain, dan pola radiasi. Hasil pengujian lalu dibandingkan dengan hasil simulasinya.

\section{Frekuensi Kerja}

Frekuensi kerja antena J-Pole ditentukan berdasarkan frekuensi yang menunjukkan nilai S-Parameter terendah berdasarkan proses simulasi. Hasil simulasi dari frekuensi kerja antena J-Pole tertera pada gambar 3. Gambar tersebut menunjukkan letak frekuensi dengan nilai SParameter terendah, yang kemudian ditentukan sebagai frekuensi kerjanya.

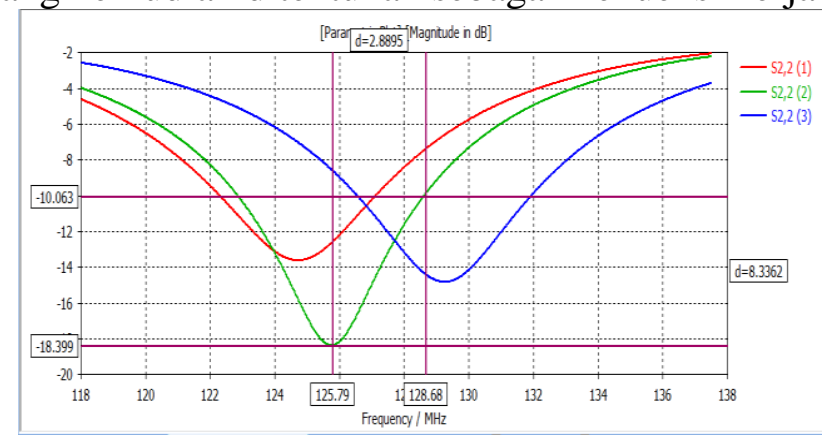

Gambar 2. Grafik pengujian S- Parameter dan frekuensi kerja

Dari grafik di atas, dapat dilihat bahwa antena J-Pole memiliki S-Parameter terendah pada 125.79 MHz untuk pita VHF Airband.

Lebar frekuensi kerja / band width ditunjukkan dari selisih nilai frekuensi terendah dari VSWR $<1: 1.5$ dan nilai frekuensi tertinggi dari VSWR $<1: 1.5$.

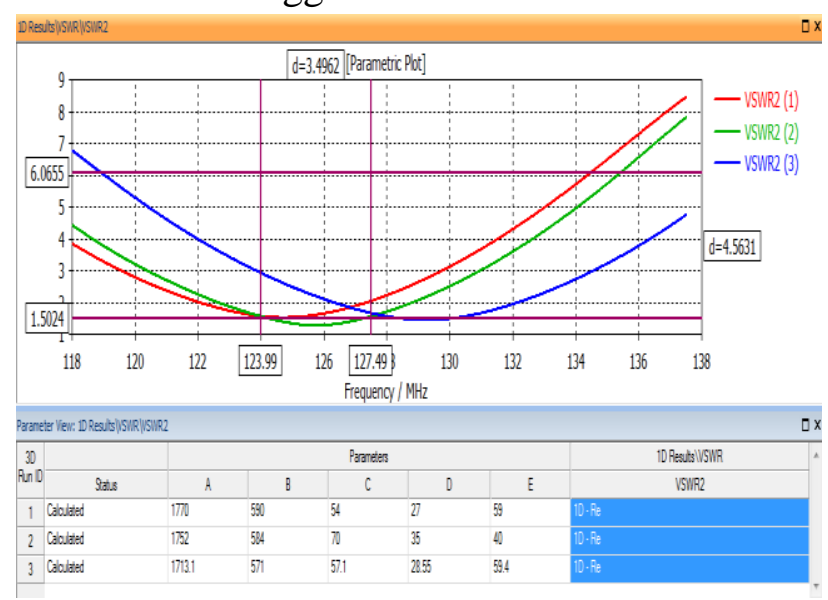

Gambar 3. Grafik pengujian VSWR dan frekuensi kerja

Dari grafik di atas, dapat dilihat bahwa antena J-Pole memiliki frekuensi terendah pada VSWR<1:1.5 sebesar $123.99 \mathrm{MHz}$ dan memiliki frekuensi tertinggi pada VSWR<1:1.5 sebesar 127.49 MHz. Lebar frekuensi kerja / band width ditunjukkan dari selisih nilai 
frekuensi terendah dari VSWR $<1: 1.5$ dan nilai frekuensi tertinggi dari VSWR $<1: 1.5$.sebesar 3.49 Mhz. Nilai ini masuk ke dalam lebar band frekuensi aerodrome surface communication.

\section{Voltage Standing Wave Ratio (VSWR)}

Pada proses simulasi, VSWR antena J-Pole ditentukan berdasarkan nilai VSWR terendah dari rentang frekuensi uji yang telah ditetapkan pada perancangan pita frekuensi sebelumnya. Nilai VSWR yang diharapkan adalah mendekati 1:1, yang menunjukkan kesesuaian impedansi antena dengan saluran transmisinya. Hasil simulasi VSWR antena J-Pole dapat dilihat pada gambar 5 .

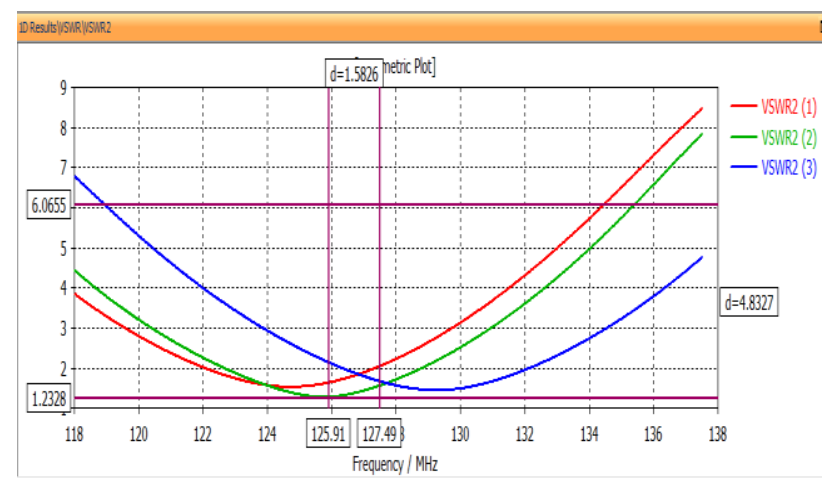

Gambar 4. Grafik simulasi VSWR

Dari grafik di atas, dapat dilihat bahwa antena J-Pole memiliki VSWR terendah sebesar 1:1.23 pada frekuensi $125.91 \mathrm{MHz}$.

\section{Return Loss}

Return loss adalah perbandingan antara amplitudo dari gelombang pantul terhadap gelombang yang dipancarkan (Kraus, 1988). Return loss dari suatu antena dapat ditentukan berdasarkan nilai return loss terendah pada rentang frekuensi tertentu. Berdasarkan hasil simulasi pada CST Microwave Studio, return loss antena J-Pole ditentukan berdasarkan nilai S2,2 terendah pada grafik S-Parameter. Hasil simulasi antena J-Pole dapat dilihat di gambar 6.

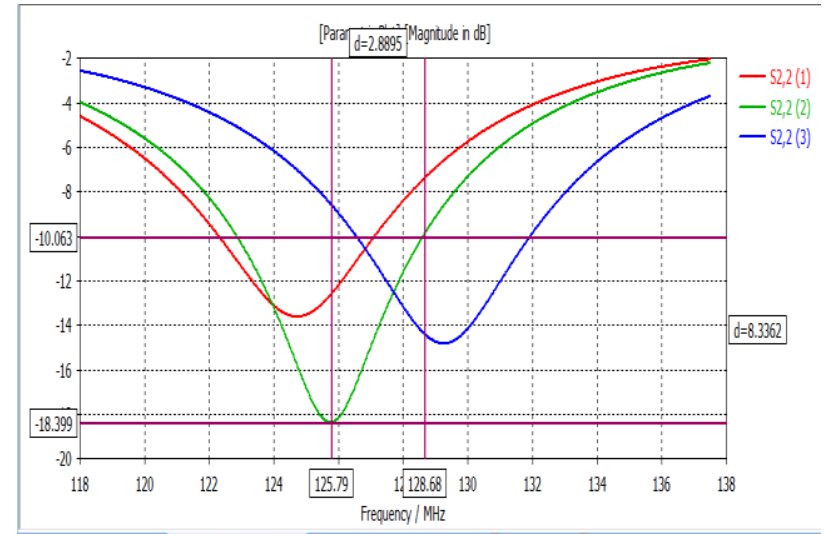

Gambar 5. Grafik simulasi Return loss

Dari hasil simulasi diketahui bahwa frekuensi dengan nilai return loss terendah juga merepresentasikan frekuensi kerja antenna. 


\section{Gain}

Gain dari suatu antena dideskripsikan sebagai perbandingan antara intensitas radiasi maksimum dari antena yang akan diuji gainnya terhadap intensitas radiasi maksimum suatu antena referensi dengan masukan daya yang sama (Balanis, 2005). Gain antena hasil simulasi pada frekuensi $126 \mathrm{MHz}$ sebesar 3,03 dB.

\section{Pola Radiasi Antena J-Pole}

Pola radiasi dideskripsikan sebagai distribusi spasial kuat sinyal yang diterima oleh suatu antena (Sawyer, 2007). Pola radiasi yang disimulasikan pada penelitian ini adalah pola pada bidang elevasi $\varphi=90^{\circ}\left(\theta=0^{0}-360^{\circ}\right)$ dan pada $\theta=90^{\circ}\left(\varphi=0^{\circ}-360^{\circ}\right)$. Berdasarkan proses simulasi, didapatkan pola radiasi antena J-Pole seperti terlihat pada Gambar dibawah
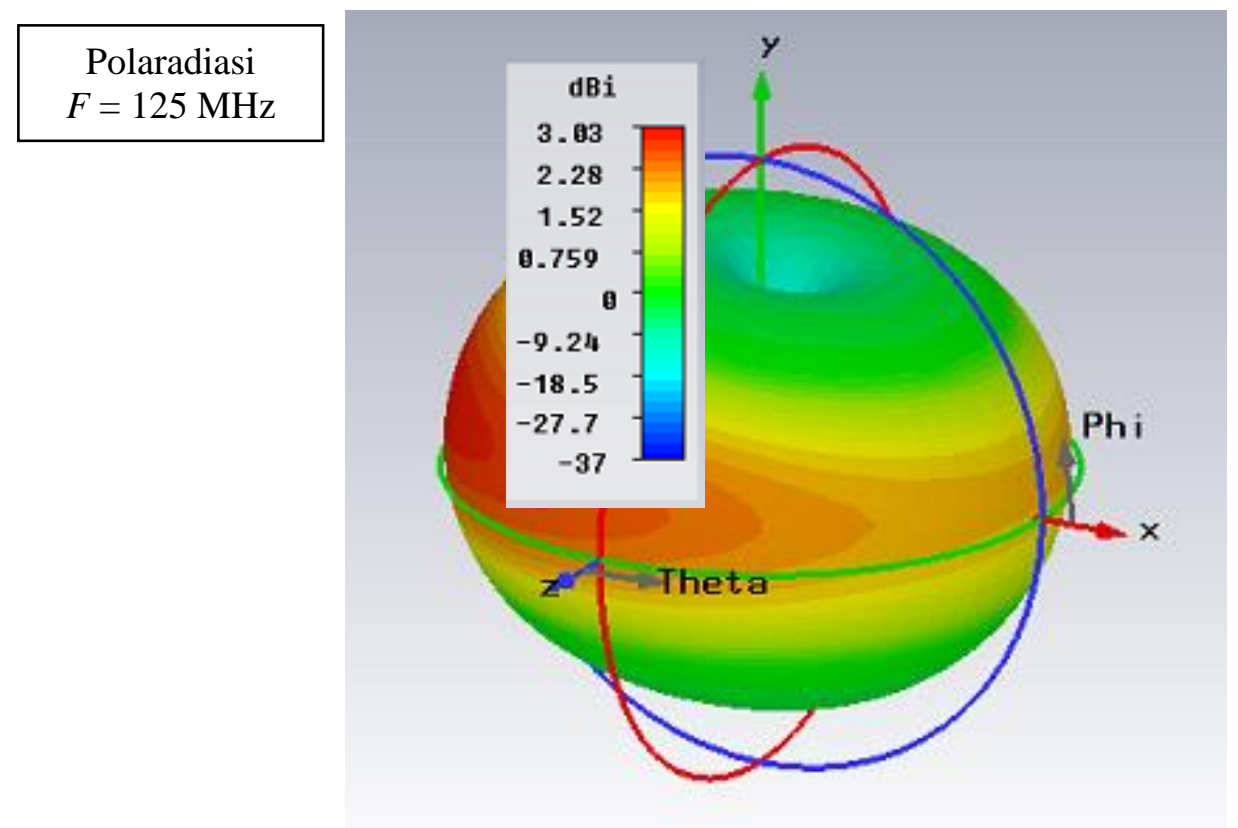

Gambar 6. Gain dan polaradiasi antena hasil simulasi

Dari Gambar 6 di atas terlihat bahwa hasil simulasi menunjukkan bahwa antena J-Pole beradiasi ke semua arah, namun level dayanya tidak sama pada tiap sudutnya. Hasil simulasi pola radiasi sudah sesuai dengan teori tentang antena J-Pole yang mempunyai pola omnidirectional (Fong, 2003).

\section{KESIMPULAN}

Dari 3 rancangan yang diuji dengan simulasi software CST2014 diperoleh nilai optimal untuk frekuensi kerja $126 \mathrm{MHz}$ pada rancangan ke dua. Rancangan dengan dimensi $\mathrm{A}=1752 \mathrm{~mm}$, $\mathrm{B}=584 \mathrm{~mm}, \mathrm{C}=70 \mathrm{~mm}, \mathrm{D}=35 \mathrm{~mm}$ dan $\mathrm{E}=40 \mathrm{~mm}$ dengan bahan besi $(\mathrm{Fe})$ mampu beroperasi pada frekuensi VHF $126 \mathrm{MHz}$ dengan bandwidth 3.49 Mhz. Frekuensi kerja maksimal pada 125.9 Mhz dengan nilai VSWR 1.23. Gain hasil simulasi pada frekuensi $126 \mathrm{Mhz}$ adalah 3,08 dB. Hasil ini berbeda dengan hasil perhitungan dimensi antenna J-Pole untuk frekuensi 126 $\mathrm{MHz}$ berdasar teori yang ada.

\section{DAFTAR PUSTAKA}

Balanis, C. A. (2005). Antena Theory: Analysis and Design, 3rd Edition. new jersey: John Wiley and Sons, Inc. 
Fon, Edison (2003) The DBJ-1: A VHF-UHF Dual-Band J-Pole. ARRL

Griffith, A. S. (2000). A 146 and $445 \mathrm{MHz}$ J-Pole Antenna. QST.

Kraus, J. D. (1988). Antennas, 2nd Edition . New Delhi: Tata McGraw-Hill.

Kubichek, D. (2008). The Simple 2m/440 Copper Pipe "J". .

Lesmana, R. (2009). Antena J-Pole untuk $70 \mathrm{~cm}$ Band atau $2 \mathrm{~m}$ Band. . Jakarta.

Rahman, M. R. (2014, April 5). berita. Retrieved july 17, 2018, from antaranews.com: http://www.antaranews.com

Reynante, J. (1994). An Easy Dualband VHF/UHF Antenna. . San Diego.

Sawyer, Jesse and Eugeny Sosnovsky, "Omnidirectional

Horizontally Polarized UHF Antenna Design”, Bachelor

Thesis, Worcester Polytechnic Institute, Massachusetts,

United States, Oktober. 2007

System, N. G.-P. (2014, august 12). parkair system. Retrieved july 17, 2018, from plannetcom.com: http://www.northropgrumman.com/international

Volakis, U. O.-C. (2012). Design of an efficient ambient WiFi energy. IET Microwaves, Antennas \& Propagation , 1200-1206.

Yoga Krismawardana, Y. C. (2015). Perancangan Dan Analisis Antena J-Pole Dualband Dengan Variasi Bentuk "T” Untuk Komunikasi Radio Transceiver Pada Pita Vhf Dan Uhf. Transmisi , 21-29. 